\title{
HEALTHCARE ACCESSIBILITY SHORTFALLS AND HOSPITAL INFRASTRUCTURES IN CHILE*
}

\author{
DEFICIENCIAS EN ACCESIBILIDAD A LA ASISTENCIA SANITARIA E \\ INFRAESTRUCTURAS HOSPITALARIAS EN CHILE
}

\section{STEFANO MAINARDI ${ }^{* *}$ \\ UKSW - Card. S. Wyszyński University, Warsaw}

\begin{abstract}
To measure healthcare accessibility, a previous study formulated a stochastic cost frontier model, and applied it to distances of communal centres from nearest emergency hospitals in Chile. Based on a larger set of variables, this study re-estimates the distance threshold, and tests alternative specifications and distribution assumptions over the period 2000-05. Complementing the analysis, ordered probit regressions help examine the cross-commune allocation of hospitals with varying complexity of medical services. Thirdly, excess distance estimates are used with other covariates in tobit models of health sector infrastructure investments. Socio-economic, demographic and geophysical conditions, along with non-hospital healthcare facilities, explain spatial inequality of hospitals. Excess distances are robust to different model specifications and distribution assumptions, and do not appear to be compensated by standards of services of the nearest hospitals or new healthcare infrastructure and upgrading investments in support to the communes concerned. Communes with perceived inadequacy in timing of medical attention turn out to often register large location inefficiency too. For the most critical communal cases, the excess distance burden amounts
\end{abstract}

* This research was partly undertaken while the author was at UCN (Universidad Católica del Norte), Antofagasta, Chile. The author thanks a referee for helpful comments and suggestions on an earlier version.

** Dept. of Informatics and Econometrics, UKSW - Card. S. Wyszyński University, Warsaw. Email: smainardi@interia.pl 
to nearly $80 \%$ of the respective, commune-specific 'best practice' hospital distance estimates.

Keywords: Healthcare services and infrastructure, stochastic frontier hurdle, inequality.

JEL Classification: $C 24-25, C 49, H 44, I 11$.

\section{Resumen}

Para medir la accesibilidad a la asistencia sanitaria, un estudio anterior formula un modelo de frontera estocástica de costes, y lo aplica a las distancias entre centros comunales y los hospitales de emergencia más cercanos en Chile. Basándose en un mayor número de variables, este estudio reestima el umbral de distancia, y evalúa alternativas, especificaciones y supuestos distributivos relativos al período 2000-05. Complementando ese análisis, regresiones de probit ordenado permiten examinar la asignación entre comunas de hospitales de diferente complejidad de servicios médicos. En tercer lugar, se utilizan las estimaciones de distancias en exceso, junto a otras covariantes, en modelos tobit sobre inversiones infraestructurales en el sector sanitario. La desigualdad espacial de los hospitales es explicada por diferentes condiciones socioeconómicas, demográficas y geofísicas, y por la presencia de servicios sanitarios no-hospitalarios. Las distancias en exceso resultan no variar sensiblemente según diferentes especificaciones y supuestos distributivos, ni ser compensadas por estándares de servicios de los hospitales más cercanos o por nuevas inversiones o mejoramientos en infraestructuras sanitarias en las comunas afectadas. Comunas con percepciones difusas de inadecuado manejo del tiempo en la atención médica presentan a menudo también largas ineficiencias de localización. En los casos comunales más críticos, la carga de exceso de distancia alcanza cerca del $80 \%$ de los estándares estimados de 'mejores prácticas' para las respectivas distancias hospitalarias comunales.

Palabras Clave: Servicios e infraestructuras de salud, 'hurdle' de frontera estocástica, desigualdad.

\section{INTRODUCTION}

In several countries, the healthcare system continues to fall short of sufficiently meeting local demand for healthcare. To help design measures to redress this problem, an accessibility approach examines the location of healthcare facilities (and/or human resources for health) relative to demand for medical services (Bigman and Deichmann, 
2000; Gupta et al., 2003), ${ }^{1}$ while an imputational approach analyses the extent to which public health targets are achieved or fail to be matched, by estimating distribution weight parameters of public investments (Mainardi, 2003; for other sectors: McFadden, 1976, and Brent, 1991; alternative prioritisations and distribution weights in healthcare interventions in low-income countries are discussed in James et al., 2005). Both strands of research rely on similar underpinnings, and try to identify population subgroups poorly served and areas in need of new hospitals and infrastructure upgrading. In Mainardi (2007), a theoretical framework linking accessibility to social distribution weights in hospital infrastructure investments is formulated and partly tested with a stochastic cost frontier (henceforth SCF) hurdle model. This model is applied to estimate safety distance threshold and excess distances of communal administrative centres from the nearest emergency hospitals in Chile, over the period 2000-03.

By relying on a larger set of variables (and based on theoretical developments from the above studies), this analysis tests the sensitivity of earlier results to alternative SCF hurdle specifications and distribution assumptions. The research focus is broadened towards an assessment of government revealed preferences in the cross-commune distribution of (i) hospitals with different standards of medical care and (ii) new healthcare infrastructure investment. The two issues are analysed with ordered probit models on a zero-censored ranking proxy for main hospital/healthcare type available in a commune, and tobit regressions on the share of local healthcare infrastructure expenditures in total municipal health budget outlays, respectively. The next section reviews theoretical and operational measures of healthcare access shortfall and related estimation problems. Findings of previous studies for Chile and hypotheses of concern, partly related to these studies, are considered in section III. Section IV presents estimation results, based on pooled biennial (2000-05) commune-level data. Besides physical distances, the analysis relies on information on constraints in ease and speed of access, due to problems of transport links and/or road infrastructure with regional centres and perceived timing of medical attention. Conclusions are drawn in section $\mathrm{V}$.

\section{HOSPITAL ACCESS SHORTFALLS AND INEQUALITY: MEASUREMENT AND ECONOMETRIC ESTIMATION}

Among alternative indices of access shortfall, specific theoretical advantages are intrinsic to the Atkinson-Kolm-Sen (AKS) family of normative inequality indices based on equally distributed equivalent (EDE) distance (see the Appendix). An AKS hospital distance-inequality index measures the share of hospital distances which

1 Equitable access (defined as equal access for equal needs [in terms of health status]) to healthcare services is a multi-dimensional concept fraught with contending issues, whose debate lies beyond the scope pursued here (Oliver and Mossialos, 2004; Savedoff, 2007; Thiede and McIntyre, 2008). While other aspects can be analysed better at a more disaggregate level (e.g. affordability, cost-effectiveness of services, cultural acceptability), this analysis is focused on physical accessibility to healthcare, i.e. existence of healthcare services of specific standards within reasonable reach of users. 
could be avoided with social indifference if the remainder were distributed equally, i.e. the percentage welfare loss of access inequality. If $D_{E}$ and $D_{A}$ are the EDE and the cross-population average hospital distance, respectively, this index is given by:

$$
I(D)=1-\left(D_{E} / D_{A}\right)
$$

In practice, the EDE distance is not observed. Authorities' allocation planning of emergency hospitals can be assumed to trace a hurdle-type decision-making process. Up to a safety distance threshold (e.g. 4 or $5 \mathrm{~km})$, a latent variable $\left(D_{j}{ }^{*}\right)$ reflects the local regulators' perceptions as to whether there is a need for major hospital facilities within this threshold in a target area, given local (e.g. communal) geo-demographic features (expressed by population size and degree of geographical dispersion of the communal population: see variables lnpop and $\operatorname{disp}(j)$ in Table 2) and the availability of minor, partly supplementary healthcare centres (reflected by the variable hsavail in Table 2). ${ }^{2}$ Beyond this threshold in areas where the 'hurdle is crossed', the true travel/ time cost-minimising frontier is not observed, but best practice reference distances can be estimated through SCF modelling, as empirical proxies for target area-level EDE distances. Hence, sources of spatial inequality in healthcare access can be assessed, after controlling for the same benchmark variables used for the first (binary-type) stage of the healthcare infrastructure planning process. Excess distances are measured by the conditional mean of the skewed stochastic (inefficiency) term $\left(\mathrm{E}\left[u_{j} \mid v_{j}+u_{j}\right]\right){ }^{3} \mathrm{An}$ asymmetry parameter (expressed as $\gamma=\sigma_{\mathrm{u}}{ }^{2} /\left(\sigma_{\mathrm{v}}{ }^{2}+\sigma_{\mathrm{u}}{ }^{2}\right)$, or $\lambda=\sigma_{\mathrm{u}} / \sigma_{\mathrm{v}}$, i.e. 'signal-tonoise' ratio) reflects the relative importance of the inefficiency component.

As in other applications of SCF modelling, two interrelated problems bear potential implications for the estimation of hospital location-inefficiency scores. ${ }^{4}$ First, a

2 The average safety threshold reflects regulators' views on individual-varying safety distance thresholds $z_{i}$, with no change of utility ceteris paribus within these limits (e.g., passing from 1 to $3 \mathrm{~km}$ ), and increasing marginal disutility beyond them. In experimental/behavioural economic terms, individual-varying distance thresholds can be observed based on perceptions of waiting time within $e . g$. a heterogeneous group of consumers (Oxoby and Bischak, 2005). Also, the time required to reach a healthcare facility is a relevant determinant of individuals' perceived access to these services (Savedoff, 2007).

3 In stochastic production frontier models, the conditioning composed error is instead $v_{j}-u_{j}$ (Jondrow et al., 1982). If the quantity and quality of locally available healthcare facilities and geophysicaldemographic control variables are included in a vector of variables $Z_{j}$, a stochastic distance frontier hurdle model can be expressed as (with $r>0, \theta>0$ ):

$$
\begin{gathered}
D^{*}=\mathrm{D}(\text { geographical population dispersion, population, availability } \\
\text { of non-hospital health services })
\end{gathered}
$$

The latent variable equation [1] is defined as in the text. In [2], the positive sign superscript for $\mathrm{N}$ refers to left-truncation at zero of the skewed stochastic term $u_{j t}$, while $v_{j t}$ is a random component reflecting unsystematic influences and measurement errors (and $\eta_{\mathrm{j}}$ fixed effects). The gamma density nests the (negative) exponential distribution $(\mathrm{r}=1)$.

4 A target area (location) inefficiency (i.e. suboptimal allocation of healthcare resources) is a backlog in healthcare accessibility, which contributes to absence of spatial equity among target areas. An aspect of the interactions between healthcare efficiency and spatial equity is highlighted by the argument that 
simultaneity bias may affect the relationship between the dependent variable and one or more explanatory variables (for instance, hospital distance versus annual medical visits per capita). In this case, not all explanatory variables are strictly exogenous, and some of these variables will be correlated with the cost inefficiency term, with consequent uncertainty as to whether it is appropriate to use them to explain hospital distance (note $3: D_{j}$ ) or location inefficiency $\left(u_{j}\right)$, or both. Similarly, a two-step estimation modelling $u_{j}$ (obtained from a first-step regression estimating the distance frontier) as a function of variables which supposedly cause systematic deviations from the frontier can produce biased parameters and spuriously under-dispersed inefficiency estimates (Wang and Schmidt, 2002).

An additional source of bias can arise from correlation of unobserved individualspecific effects with one or more explanatory variables and the dependent variable. As in an omitted variable case, this induces a (heterogeneity) bias in estimated parameters of the exogenous variables. Especially in the presence of strong 'within' (time-related) variation, both fixed and random effects models as originally specified in stochastic frontier analysis fail to distinguish between unobserved heterogeneity and inefficiency, with possibly overestimated inefficiency scores in the fixed effects model.$^{5}$ However, if inefficiency is persistent, it is likely to be largely absorbed by the time-invariant fixed or random effects, thus producing underestimated inefficiency scores in over-parameterised panel data models, with no ideal procedure suited to disentangle invariant and time-varying elements associated with either heterogeneity or inefficiency. Relative to healthcare services and this analysis, hospital distances register few changes over a short sample period, and $\mathrm{T}<4$ (for $T$ biennia), i.e. lower than a reasonable minimum even for unbalanced panel data modelling (Farsi, Filippini and Kuenzle, 2004: 8). Unobserved heterogeneity is accounted for by commune- and region-specific time-invariant regressors and time dummies.

Inefficiency estimates can also be sensitive to distribution assumptions of the lefttruncated stochastic error component. Alternative asymmetric densities are theoretically acceptable, with the standard half-normal and the exponential distributions implying a higher average efficiency relative to non-monotonic distribution analogues, due to their zero modal point and near-zero concentration. More parameterised stochastic frontier models are bound to face identification problems in maximum likelihood (ML) estimation, unless very large sample sizes are available (Ritter and Simar, 1997). The truncated-normal density allows a more flexible modelling, without an a priori zerorestriction for the mean of the inefficiency term (Baccouche and Kouki, 2003). In the exponential model, the range of inefficiency scores can be wider, but the frequency of high inefficiency scores tends to be lesser than under half- or truncated-normal distributional assumptions.

"variations in efficiency [of public services] may lead to unequal quality of services and a consequent perception of unfairness' (Smith and Street, 2005: 402).

5 Greene (2003: 11-15) reviews these problems and proposes a new generalised random effects multilevel specification, geared to better account for unobserved heterogeneity (in the production/cost function or the inefficiency distribution). 
Most studies on the subject tend to focus on possible mismatching effects of the spatial distribution of public facilities relative to local demand and the quality of access roads. However, non-physical issues of service provision are equally relevant, including adequacy of these services in terms of cross-individual preferences, and transparency of the information about medical care availability. Even if only the geographical dimension of accessibility is focused on, results can be sensitive to the selection of geographical units. Criteria for identification of service areas (as territorial units where the demand gravitates towards local facilities) range from a priori set target distances of demand from service provision to more complex measures based on georeferenced information on travel time and geographical conditions of accessibility (an example of the latter, applied to Costa Rica, is provided by Bixby and Güell, 1999). Due to the relevance of administrative subdivisions in Chilean national healthcare planning, Arteaga et al. (2002a) argue in favour of using communal boundaries, or, in the absence of commune-level information, health districts (servicios de salud, whose boundaries do not coincide with other administrative subdivisions).

\section{PREVIOUS EMPIRICAL EVIDENCE AND BASIC HYPOTHESES}

An in-depth and thorough statistical analysis on the healthcare sector in Chile is hindered by insufficient statistical information relative to a large number of communes, which are not covered by national censuses in past years, and lack of longitudinal data. Out of 341 communes in the country, 143 were not included in the 1998 socioeconomic characterisation survey (CASEN): as rural and remote, these communes, while representing only $10 \%$ of the population, are likely to be particularly concerned with problems related to difficult accessibility to adequate healthcare facilities. More recently, CASEN cross-commune coverage has improved, with this coverage reaching 302 communes in 2003 and 326 communes in 2006 (Mideplan, 2004 and 2006). ${ }^{6}$ However, due to smaller population size, for many newly covered communes demographic variables tend to be less stable over time. General features of studies on Chile's public health and healthcare system are summarised in Table 1, and related results are commented hereafter.

Geographical disparities in health status are found to be largely associated with different socioeconomic conditions, and to concern both in-patient medical care, and visits to primary care physicians and specialised doctors, with substantial gaps between relatively richer and poorer communes within and across Regions. Only $20 \%$ of the country's healthcare consulting capability is used to treat $60 \%$ of the population living in Regions outside the Metropolitan area of Santiago (i.e. $40 \%$ of Chile's

6 This analysis adopts the administrative subdivision prevailing over the sample period, with 341 communes. Relative to 2005, SINIM reports statistical information for four newly established communes, formed within the boundaries of one existing commune each (the latter indicated in parentheses here): Alto Hospicio (Iquique, Reg. I), Hualpén (Talcahuano, Reg. VIII), Alto Biobío (Santa Bárnaba, Reg. VIII) and Chonchol (Nueva Imperial, Reg. IX). To maintain time series consistency, data have been aggregated based on the relative demographic weights of the two communes in each case. 


\section{TABLE 1}

\section{HEALTH STATUS AND HEALTHCARE SYSTEM INEQUALITIES IN CHILE: OVERVIEW OF PREVIOUS STUDIES}

\begin{tabular}{|c|c|c|c|c|}
\hline indicators & method & geographical unit & period & source \\
\hline $\begin{array}{l}\text { socioeconomic, } \\
\text { public spending } \\
\text { and healthcare } \\
\text { system }\end{array}$ & $\begin{array}{l}\text { descriptive } \\
\text { statistics }\end{array}$ & 318 communes & 1990-96 & Bossert (2000) \\
\hline $\begin{array}{l}\text { health status and } \\
\text { public health risk }\end{array}$ & $\begin{array}{l}\text { descriptive } \\
\text { statistics and } \\
\text { correlation analysis }\end{array}$ & 335 communes & 1994-98 & $\begin{array}{l}\text { González et al. } \\
\text { (2000) }\end{array}$ \\
\hline $\begin{array}{l}\text { socioeconomic and } \\
\text { healthcare system }\end{array}$ & $\begin{array}{l}\text { descriptive } \\
\text { statistics and } \\
\text { projections to } 2005\end{array}$ & $\begin{array}{l}28 \text { health districts } \\
13 \text { Regions }\end{array}$ & 1992-97 & $\begin{array}{l}\text { Arteaga, Astorga } \\
\text { and Pinto (2002) }\end{array}$ \\
\hline $\begin{array}{l}\text { a. socioeconomic } \\
\text { and public health } \\
\text { b. heath status and } \\
\text { healthcare system }\end{array}$ & $\begin{array}{l}\text { descriptive } \\
\text { statistics and } \\
\text { correlation analysis }\end{array}$ & $\begin{array}{l}\text { (for a) } 198 \\
\text { communes; } \\
\text { (for b) } 28 \text { health } \\
\text { districts }\end{array}$ & 1998 & $\begin{array}{l}\text { Arteaga et al. } \\
\text { (2002a) }\end{array}$ \\
\hline $\begin{array}{l}\text { health status and } \\
\text { socio-demographic }\end{array}$ & $\begin{array}{l}\text { descriptive } \\
\text { statistics }\end{array}$ & $\begin{array}{l}13 \text { Regions } \\
\text { (random sample of } \\
3600 \text { individuals) }\end{array}$ & 2003 & $\begin{array}{l}\text { MINSAL-PUC } \\
\text { (2004) }\end{array}$ \\
\hline $\begin{array}{l}\text { socio- } \\
\text { demographic, } \\
\text { geophysical and } \\
\text { healthcare system }\end{array}$ & $\begin{array}{l}\text { stochastic frontier } \\
\text { hurdle regressions }\end{array}$ & 341 communes & $2000-03$ & Mainardi (2007) \\
\hline
\end{tabular}

population, since one third is concentrated in the latter area). The scope for access to private healthcare tends to diminish with greater dispersion of the population -in rural areas, especially in the South-, and in the presence of specific socio-demographic characteristics (such as a higher percent share of aged individuals), mostly associated with a predominance of public healthcare, where the insurance premium is unrelated to health status (Arteaga, Astorga and Pinto, 2002, and Arteaga et al., 2002a).

Despite a compensation fund for redistribution of public revenues across communes, public spending at the communal level reflects socioeconomic disparities, and is only partly offset by cross-province budget allocation decisions by the central government. According to Bossert (2000), this does not necessarily imply a regressive distribution impact of decentralisation of the healthcare system, since it concerns only the richest $10 \%$ of Chilean communes (as opposed to the others) and is partly explained by a fiscal substitution effect in local government budget allocations in communes which can rely on healthcare facilities directly financed by the central government. Moreover, average health status disparities may be spuriously affected by the demographic impact of internal migration. An example is given by low standardised mortality ratios 
estimated in some communes of the Region of Magallanes (Punta Arenas), which are characterised by high presence of in-migrants (González et al., 2000). ${ }^{7}$

In SCF regressions modelling hospital distances, high location-inefficiency scores are found especially in the two geographical extremes, namely the Region of Arica/Iquique in the North, and the Regions of Puerto Montt and Punta Arenas in the South (Mainardi, 2007). Once population is accounted for, communes with highly disadvantaged intra-regional geographical conditions and transport links face similar hospital distances as those with easy access to regional administrative centres, in contrast with intermediate cases. In this concern, whereas the degree of geographical dispersion of the population within individual communes (proxied by the dummy $\operatorname{disp}(j)$ : see Table 2) appears to exercise a consistent pattern in binary regressions, a non-linear relationship turns out to characterise cross-commune transport accessibility within regions (proxied by $d u m(j) a c$; similar results in this analysis: model [6], Table 3 ). The inefficiency component, which proxies unequal healthcare access, is partly explained by the extent of poverty across communes, measured by the percent share of residents of a commune living below the poverty line (relative to these and the other variables referred to here and in the next section, see the Appendix).

Apart from hitherto empirical findings for Chile, hypotheses on determinants of healthcare demand can partly be inferred also from econometric studies on other countries. Relative to healthcare demand in Costa Rica, Bixby and Güell (1999) apply a conditional logit model to patients' preferences for alternative medical centres, and find that only one third of users choose the nearest medical facility. Besides distance, patients' selection turns out to be influenced by size of the medical establishment (proxied by median number of medical office hours), its antiquity, and the variety of services offered (with hospitals being preferred to clinics). Distance appears to matter especially for dwellers in rural areas.

In terms of hypotheses complementing the above empirical evidence, once healthcare coverage, use and service quality and other control variables are accounted for, healthcare access inequality can be expected to be aggravated in target areas with relatively more serious problems of transmittable diseases (with high hepatitis and tuberculosis notification rates), poor health status (reflected to some extent by infant mortality rates), and, by definition of the stochastic frontier model, allocation inefficiency in the provision of healthcare services. As suggested by Puig-Junoy and Ortún (2003: 20), resource allocation inefficiency can be reflected by (i) excessively low (/high) ratios of nurses to medical doctors assigned to an area (accounted for by the variable nurpmd: see Table 2), thus implying shortage of nurses (/doctors) relative to a more balanced composition of healthcare personnel, or (ii) the absence of medical personnel, likely to affect especially rural first-aid posts (absmed, Table 2). An analysis of the relationships between health status/outcome and healthcare provision characteristics (such as access and quality of services) can be useful for an assessment of healthcare effectiveness across communes. Controversial issues include the effects

7 The standardised mortality ratio measures the age composition-adjusted excess (or reduced) risk of dying in a community, relative to a reference population. 
TABLE 2

LIST OF VARIABLES AND DESCRIPTIVE STATISTICS

\begin{tabular}{|c|c|c|c|c|c|}
\hline variable & definition (source) & mean & s.dev. & skewness & kurtosis \\
\hline \multicolumn{6}{|c|}{ a. Socioeconomic indicators } \\
\hline aiws & $\begin{array}{l}\text { access to drinkable water pipe (\% } \\
\text { dwellings; SINIM) }\end{array}$ & 65.6 & 24.22 & -0.37 & 2.07 \\
\hline lit & $\begin{array}{l}\text { literacy rate }(\% \text { literate in } 10+\text { aged } \\
\text { population; SINIM)** }\end{array}$ & 0.85 & 0.09 & -0.54 & 3.58 \\
\hline schly & average years of schooling (SINIM) & 8.02 & 1.43 & 0.75 & 3.55 \\
\hline hcpov & $\begin{array}{l}\text { poverty headcount ( } \% \text { population living } \\
\text { below the poverty line, SINIM) }\end{array}$ & 25.12 & 10.35 & 0.3 & 2.94 \\
\hline hcpovurb & $\begin{array}{l}\text { poverty headcount for urban areas } \\
\text { (Agostini, Brown and Góngora 2008: } \\
\text { Ap. 4) }\end{array}$ & 33.46 & 9.38 & -0.4 & 3.38 \\
\hline hcpovrur & $\begin{array}{l}\text { poverty headcount for rural areas } \\
\text { (Agostini, Brown and Góngora 2008: } \\
\text { Ap. 4) }\end{array}$ & 22.58 & 9.3 & 0.16 & 2.31 \\
\hline ipovr & $\begin{array}{l}\text { extent of absolute poverty within poor (\% } \\
\text { indigent in total poor; SINIM) }\end{array}$ & 27.1 & 9.94 & 0.35 & 3.62 \\
\hline \multicolumn{6}{|c|}{ b. Demographic and geophysical conditions (see also dummies) } \\
\hline birthr & birth rate (per thousand residents; SINIM) & 14.8 & 3.63 & 0.35 & 10.37 \\
\hline epr & $\begin{array}{l}\text { elderly }(65+\text { aged }) \text { population rate } \\
(D E I S)^{* *}\end{array}$ & 0.08 & 0.02 & 0.26 & 3.91 \\
\hline fpopr & female population rate $(S I N I M)^{* *}$ & 0.48 & 0.05 & -3.98 & 23.15 \\
\hline lnarea & area $\left(\mathrm{km}^{2} ;\right.$ SINIM $)$ & 6.26 & 1.62 & -0.47 & 3.43 \\
\hline lnpop & population (number of residents; SINIM) & 9.85 & 1.37 & -0.13 & 3.23 \\
\hline urb & $\begin{array}{l}\text { urbanisation rate }(\% \text { population, } 100 \%=1 \text {; } \\
\text { SINIM)** }\end{array}$ & 0.6 & 0.3 & -0.37 & 2.1 \\
\hline \multicolumn{6}{|c|}{ c. Healthcare provision: institutional features, availability, location and quality perceptions (see also dummies) } \\
\hline dist & distance of communal administrative & 3.01 & 3.92 & 2.79 & 12.93 \\
\hline (lndist) & $\begin{array}{l}\text { centre from the nearest reference or } \\
\text { emergency hospital (dist 1:10 km } \\
\text { distance; lndist log-transformed km } \\
\text { distance; SINIM) }\end{array}$ & (2.6) & $(1.43)$ & $(-0.4)^{*}$ & $(2.3)$ \\
\hline hsavail & $\begin{array}{l}\text { non-hospital health service availability } \\
\text { (weighted average of general urban/rural } \\
\text { clinics and rural first-aid posts, per } 10000 \\
\text { residents, with weight parameters } 1,1 \text { and } \\
0.2 \text {, for the three facilities respectively; } \\
\text { SINIM) }\end{array}$ & 1.14 & 1.13 & $2.25^{*}$ & 10.86 \\
\hline absimp & $\begin{array}{l}\text { perceived absence of improvements in } \\
\text { public hospitals and medical centres ( } \% \\
12+\text { aged patients, } 100 \%=1 ; I N E)^{* *}\end{array}$ & 0.26 & 0.11 & 0.35 & 3.03 \\
\hline abstim & $\begin{array}{l}\text { perceived absence of adequate timing in } \\
\text { medical attention in public hospitals and } \\
\text { medical centres ( } \% 12+\text { aged patients, } \\
100 \%=1 ; I N E)^{* *}\end{array}$ & 0.13 & 0.07 & 1.21 & 5.58 \\
\hline nurpmd & ratio of nurses to medical doctors (SINIM) & 0.73 & 0.43 & $1.27^{*}$ & 6.7 \\
\hline
\end{tabular}




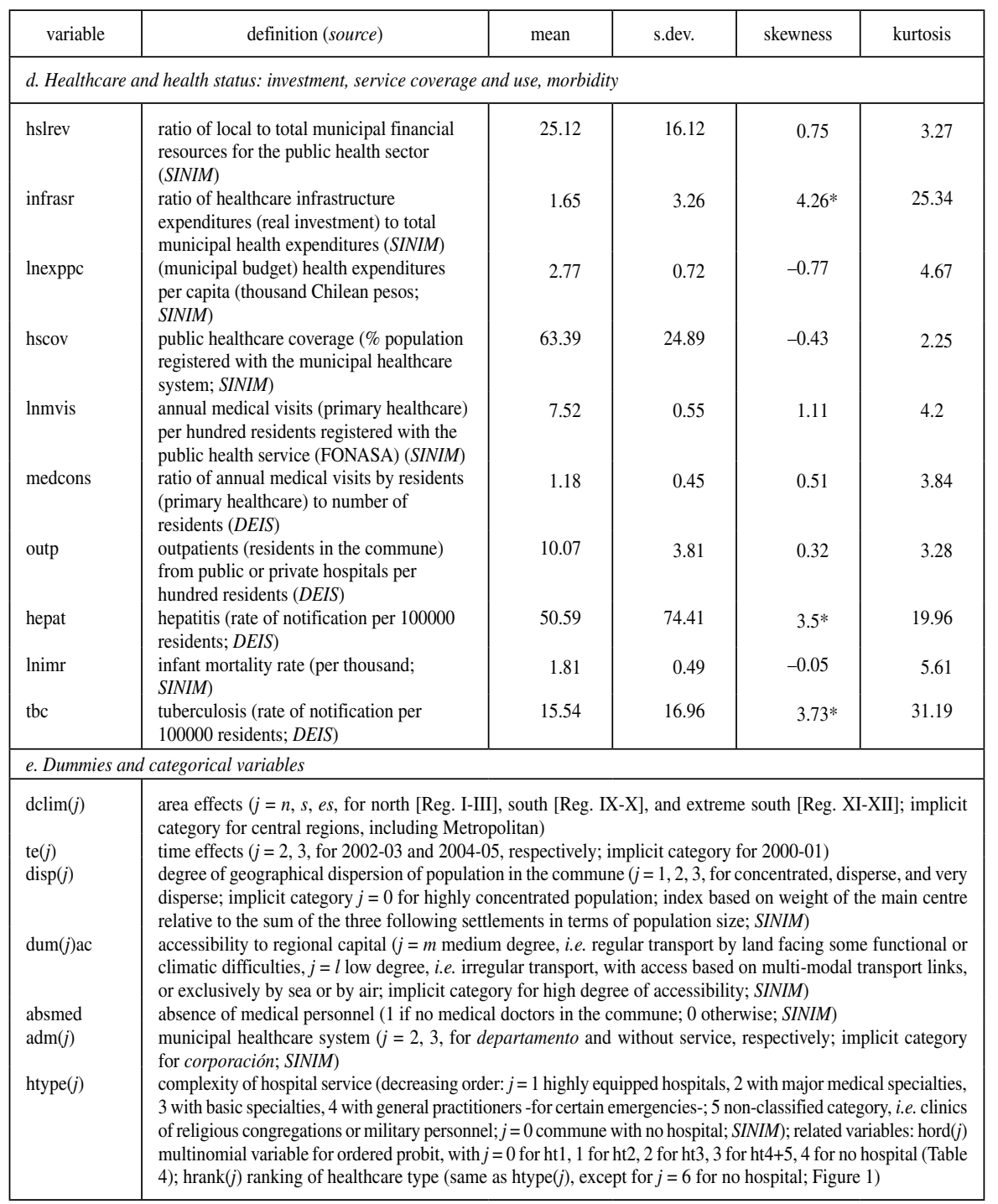

Notes: Sample: biennial 2000-05 for SUBDERE-SINIM (for lnmvis and lnimr, biennial 2002-05 and 2000-03, respectively); 2003-04 or 2004-05 for MINSAL-DEIS; 1998 for INE (CASEN); 200203 for Agostini, Brown and Góngora (2008). Variable names preceded by $l n$ : data transformed in natural logarithms. * zero-bounded variables. ** (1/100) rescaling.

Regions (regional administrative centre in parentheses): I Tarapacá (Iquique); II Antofagasta; III Atacama (Copiapó); IV Coquimbo (La Serena); V Valparaíso; VI Libertador Gen. B. O’ Higgins (Rancagua); VII del Maule (Talca); VIII Biobío (Concepción); IX de la Araucania (Temuco); X de los Lagos (P.to Montt); XI Aisén (Coyhaique); XII Magallanes (Punta Arenas); Metropolitana (Santiago). 


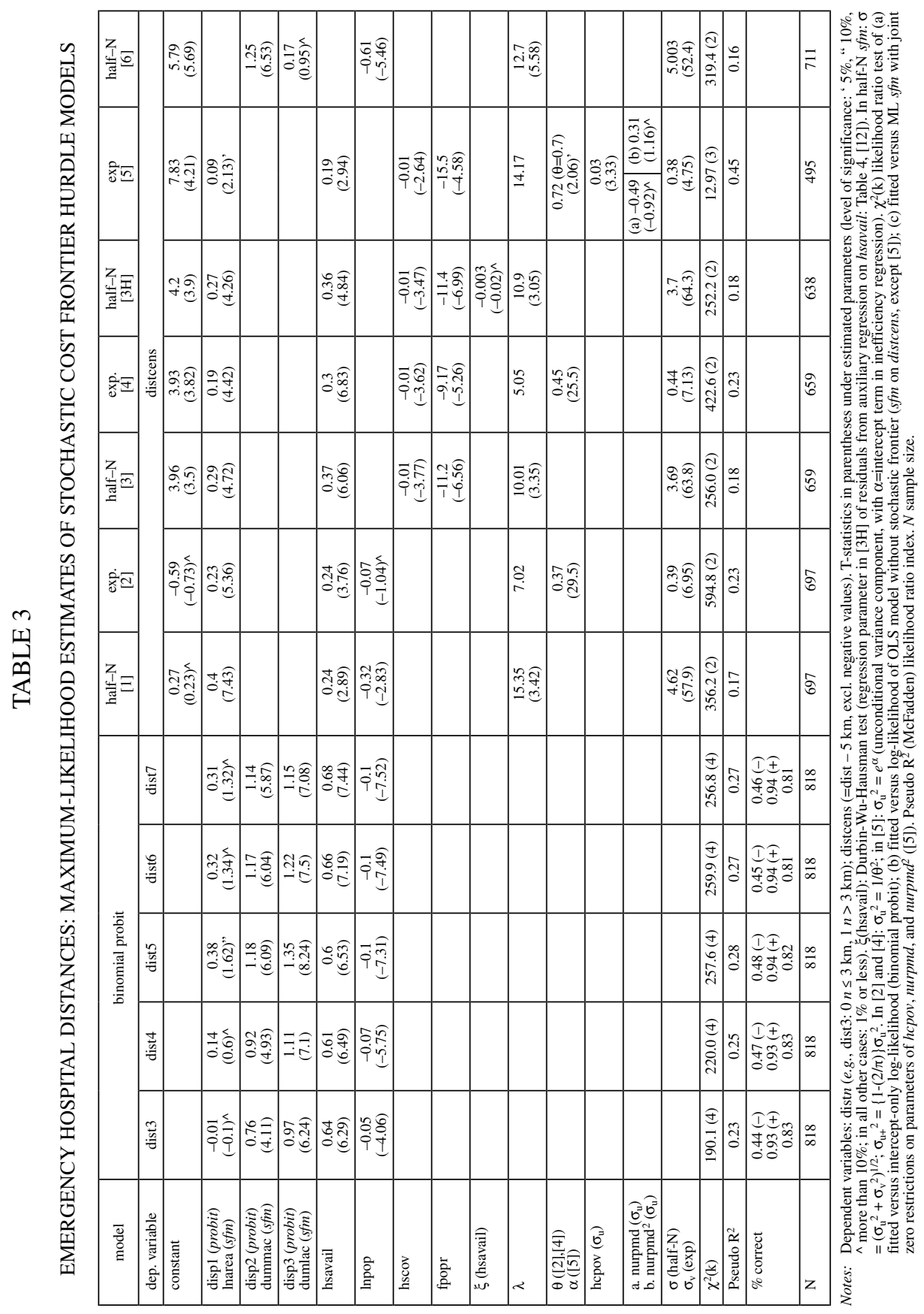


of decentralisation of the healthcare system, and the role of public financing of health expenditures for efficiency in healthcare delivery (Berger and Messer, 2002).

Among possible control variables, in view of the two-tier healthcare insurance system in Chile, the public healthcare coverage rate (hscov, Table 2) can be regarded as a proxy for healthcare expenditure allocation by residents of a commune between public and private sectors, thus reflecting cross-commune population heterogeneity (Greene, 2003: 3). Since territorial and population characteristics are likely to be related to the effectiveness of medical visits, additional control variables may include socioeconomic and demographic indicators, besides dummies for geophysical conditions (Table 2: $a$ and $b$ ).

An analysis of revealed preferences of the central government and local authorities should check the consistency of public investment initiatives with the target of enhancing accessibility and social fairness. Distribution weights in a social welfare function of hospital location decisions across target areas should be consistent with spatial equity at this level of analysis, besides other social welfare objectives (efficiency, intra-province equity in health care/status, numbers effect) and after accounting for socio-demographic features. In a more complex way than other areas of poverty targeting, the rationale for a dynamic imputation approach is weakened by budget and space constraints, with the location of existing facilities (and mostly also of demand points) being given. In a long-term dynamic perspective, the construction of new hospital buildings and other medical centres, along with improvements in infrastructures and personnel of existing facilities, should be guided so as to offset access shortfalls, with a view to achieving a social optimum in accessibility and location of healthcare services across target areas, among other social welfare goals. While the scope of this analysis is mainly methodological and empirical (i.e. testing, for the case of Chile, the robustness of econometric estimates of an SCF hurdle model and using its indications of access shortfalls for assessing government revealed preferences in the allocation of hospitals of different standards and new healthcare infrastructure investments across target areas), multi-objective social welfare functions are considered analytically by Brent (1986).

\section{ESTIMATION RESULTS}

\subsection{Descriptive statistics and correlation analysis}

This analysis has relied on a cross-commune panel covering the period 2000-05, based on statistical information of health insurance and medical establishment registers, demographic and health household surveys, and geo-referenced data. Original annual figures are provided by SUBDERE-SINIM (Secretariat for Regional and Administrative Development-National System of Municipal Indicators; www.sinim.cl) and MINSALDEIS (Ministry of Health-Dept. of Health Statistics and Information; deis.minsal.cl). In the latter source and for the variable on annual medical visits per hundred residents registered with FONASA, information is limited to 2002-05. For most indicators, 
data tend to vary on a two- or three-year basis (e.g. from 2002-03 to 2004-05), based on survey estimates. Due to the short time span and the low within-variation with consequent limited scope for panel data regression techniques, the analysis is limited to pooled biennial observations. All 341 communes (presently corresponding to 345 communes: see note 6) are virtually covered, except for some missing, timeinconsistent or extreme outlier observations concerning a few communes/variables (such as urbanisation rate and hospital distance for the island of Juan Fernández). The two most Southern Regions of Aisén and Magallanes have no official statistics of communal areas. A list of variables and related summary statistics are presented in Table 2 and briefly commented hereafter in this sub-section, while additional issues of data and choice of variables are considered in the Appendix.

Among the variables included in the three-biennium panel, the female population rate presents leftward skewness (due to a number of minor communes with relative shortage of female residents, such as Timaukel and Laguna Blanca in the Region of Magallanes) and platykurtosis. Similarly, low birth rates appear to characterise some communes in remote areas, e.g. San Gregorio (Magallanes). The population share of the elderly, with third and fourth moments closer to standardised Guassian values (i.e. zero skewness and kurtosis = 3), ranges from less than $2 \%$ in Cape Horn, to $18 \%$ in Providencia (Santiago). Along with another commune of the Metropolitan region (Vitacura), Providencia also registers the lowest relative extent of poverty, with a lessthan $1 \%$ headcount index over the period 2000-05. Rightward skewness and relatively heavy tails in the distribution are associated with other variables (Table 2: abstim and lnmvis, despite the log-transformation for the latter), besides five zero-bounded variables (hsavail, nurpmd, infrasr, hepat, tbc: see Table 2).

Cross-panel coefficients of correlation reveal different patterns of between-biennium variation. Relative to the first two biennia, they vary from 0.87 for the percentage of dwellings with access to drinkable water, to 0.73 for the percent share of population living below the poverty line, 0.63 for the ratio of healthcare infrastructure real investment to total municipal healthy expenditures, 0.23 for the extent of absolute poverty within the total poor population, and 0.1 for infant mortality rates. For three variables (literacy rate, extent of absolute poverty among the poor, and infant mortality), substantial changes over time suggest some caution for their use as indicators of levels of education, relative incidence of absolute poverty, and poor health status/ morbidity across Chilean communes, respectively. Unreliable recording and/or small population size in several communes are likely to affect estimates of simple correlation coefficients of two of these variables with related proxies, namely literacy rate versus average years of schooling $(r=0.18)$, and relative extent of absolute poverty versus the poverty headcount index $(\mathrm{r}=0.4)$. For infant mortality rates, an unstable pattern in relatively smaller communes is likely to be a major reason.

In a similar way, proxies for sanitation and health education related to incidence of transmittable and partly water and food-borne diseases (rates of notification of tuberculosis and hepatitis) show high year-to-year instability in several communes, and cannot be used as alternate indicators (the 2002-05 simple correlation coefficient is 0.04 ; if two atypical mid-biennium observations are left out of the sample-hepatitis 
in Tomé, Reg. VIII, tuberculosis in Timaukel, Reg. XII-, this coefficient is marginally higher, i.e. 0.06; see the Appendix). Relative to the same panel sub-period, a statistically significant correlation $(r=0.47)$ is found here between two proxies for demand and access to medical ambulatory attention in public healthcare centres (annual medical visits relative to FONASA-covered or to total residents, i.e. lnmvis and medcons in Table 2). The 1998 CASEN survey has been relied on here for cross-commune information on quality perceptions by healthcare users, which can be assumed to be relatively more applicable to the first biennium (see the Appendix). Statistically insignificant correlation $(\mathrm{r}=0.03)$ is found between perceived absence of healthcare system improvements and insufficient timely medical attention (absimp versus abstim, defined in Table 2).

As discussed in the Appendix, given the limited sample representativeness in household survey information on communal incomes (with SINIM poverty headcount estimates being based on CASEN surveys), statistically more robust poverty headcount ratios are provided by Agostini, Brown and Góngora (2008). The latter are based on a bootstrap estimation procedure which combines the 2003 CASEN household survey with 2002 census data, with separate estimates for urban and rural areas (concerning 314 and 313 communes, respectively, with several communes being classified only as either urban or rural). These estimates turn out to be respectively, on average, nearly $32 \%$ higher and $11 \%$ lower than total poverty headcount communal ratios for the biennium 2002-03 (corresponding to 278 communes for this variable, i.e. hcpov in Table 2). A statistically higher linear correlation links the total poverty headcount index to its urban (hcpovurb: $\mathrm{r}=0.8$ ) than rural (hcpovrur: $\mathrm{r}=0.7$ ) analogue. In turn, urban and rural poverty headcounts are highly collinear $(r=0.76)$, while urban poverty is negatively associated with the urbanisation rate across communes $(\mathrm{r}=-0.54)$. Ordered probit regressions on hospital type, replicated by relying on these alternate poverty headcount estimates relative to 2002-03 (with suitable restrictions accounting for multicollinearity problems), yield broadly analogous results as those based on the full panel sample, in terms of sign, approximate size and statistical significance of estimated parameters (see sub-section 4.4 and note 12).

\subsection{Stochastic cost frontier hurdle: hypothesis testing and probit estimates}

With a view to testing hypotheses as discussed in section III, two alternative SCF hurdle model specifications are applied: (i) error components models with inefficiency scores defined as non-negative truncations $u_{j t}\left(\sim \mathrm{N}^{+}\left[\mu_{\mathrm{u}}, \sigma_{\mathrm{u}}{ }^{2}\right]\right.$ or $\sim \Gamma\left[1 / \theta, 1 / \theta^{2}\right]$ : see note 3 ), and (ii) location inefficiency-effects models with $u_{j t} \sim \mathrm{N}^{+}\left[\mu_{\mathrm{jt}}, \sigma_{\mathrm{u}(\mathrm{jt})}{ }^{2}\right]$ (or the negative exponential distribution analogue), where $\mu_{\mathrm{jt}}=\mathrm{x}_{\mathrm{jt}} \delta$ (or in terms of conditional variance of the truncated error, $\ln \left[\sigma_{\mathrm{u}(\mathrm{jt})}\right]^{2}=\mathrm{x}_{\mathrm{jt}} \alpha$, as in model [5], Table 3), with $\mathrm{x}_{\mathrm{jt}}$ being a vector of variables influencing location inefficiency in a commune, which may include covariates used as regressors also in the cost function or interaction terms between regressors in the two equations (Battese and Coelli, 1995). As alternative distributional assumptions for the one-sided inefficiency proxy, the half-normal, truncated-normal, and negative exponential density are tested for this term, in both model specifications. 
Model specifications (i) and (ii) are non-nested (unless $\mathrm{T}=\mathrm{x}_{\mathrm{jt}}=1$, in a truncated-normal cross-section regression where $\left.\delta_{0}=\mu_{\mathrm{u}}\right)^{8}{ }^{8}$

The assumption of identical independent distribution for $u_{j t}$ can be tested against the presence of correlated structures, with for instance two or more inefficiency regimes across space or over time (Viswanathan et al., 2000). To this purpose, the hypothesis of time-invariant versus non-systematic linear time effects over the biennial panel has been tested here, with the latter effects eventually due to frontier shifts and/or location inefficiency shifts. Spatial effects can be partly accounted for by dummies related to broad climatic conditions (with a dummy accounting for four broad climatic zones), institutional factors concerning the municipal healthcare system, and state of the road/ transport network linking communes with the respective regional capitals.

For stochastic frontier hurdle modelling with an endogenously determined distance threshold, probit regressions are first applied, so as to detect an average distance threshold (when users start facing increasing marginal disutility on average). These are followed by SCF regressions on the threshold-censored distance variable (based on probit results, if applicable), which partly rely on the same covariates used in probit models. Selected results are presented in Table 3. In Mainardi (2007), relative to 2000-03 data, a grid search with binary choice models in the kilometre range $(3,7)$ indicates $5 \mathrm{~km}$ as a cross-commune safety distance threshold. In this analysis, probit estimates lend (even if only marginal) support to this selection, which coincides with or is close to a priori chosen thresholds in other healthcare accessibility studies (Bigman and Deichmann, 2000; Puig-Junoy and Ortún, 2003). With non-observable location factors for hospitals within short distances, relatively stronger predictive power of probit regressions is expectedly found for observations beyond the respective thresholds examined in the grid search (Table 3).

\subsection{Stochastic cost (censored-distance) frontier estimates}

Consistently with the increasing marginal disutility assumption, only the untransformed $5 \mathrm{~km}$-censored hospital distance variable yields convergent ML estimates (unlike log-transformed data). ${ }^{9}$ No robust convergence is obtained for models with a

8 The likelihood ratio test follows a mixed chi-square distribution if the null hypothesis refers to points on the boundary of the feasible parameter space, with critical values provided by Kodde and Palm (1986). This concerns the testing of the zero null for the asymmetry parameter defined in section II $(\gamma=0$ vs. $\gamma>0$; analogously for $\lambda$ ), with this hypothesis implying a standard mean-response function with no need for a stochastic frontier. If model (ii) is adopted, this result can be due to overall lack of inefficiency (if $\delta=0$ for all $\mathrm{x}_{\mathrm{j} t}$, including the constant term, in the inefficiency regression), or presence of non-stochastic inefficiency. Provided that explanatory variables are correctly chosen and specified, non-random inefficiency effects entail lack of identification of the constant term, so that no rejection of a zero restriction on this term can be interpreted as indirect support for the alternative hypothesis (Battese and Coelli, 1995).

9 By contrast, in a multinomial choice setting, a patient's weight to equal differences in distances is likely to decline with increasing hospital distances, thus supporting the use of log-transformed distances, e.g. for mixed logit models (Howard, 2005). Relative to stochastic frontier modelling, since iterative ML estimation may encounter convergence problems due to different magnitudes in the variables involved, the variable dist (and its censored analogue distcens) is rescaled downwards, in terms of tens of $\mathrm{km}$ 
truncated-normal density for the inefficiency proxy, for both alternative mathematical forms of the dependent variable. Over the sample period 2000-05, parameter estimates do not substantially differ from those based on the 2000-03 panel, with no role of time effects in either one of the two functions in the location inefficiency-effects model (censored distance and location inefficiency, i.e. [2] in note 3 augmented with an equation explaining the inefficiency scores: point (ii) in sub-section 4.2). After accounting for the effects of dependent variable rescaling on estimated intercept, dummies and parameter $\theta$ (see notes 3 and 9), estimation results are similar to previous findings, when comparable in terms of SCF hurdle regression, or relative to the inefficiency equation in the above re-specified model subject to alternate cost frontier regressions and distribution assumptions (e.g. model [5]-Table3 in this analysis vs. [5]-Table2 in Mainardi, 2007).

Demographic and geophysical features have a definite influence on emergency hospital locations. Once a commune's territorial size and population, or population heterogeneity in terms of municipal health insurance system and gender composition, are accounted for, residents of communes relatively farther away from these hospitals tend to be 'compensated' with greater availability of non-hospital healthcare services (Table 3: see parameter estimates for hsavail in [1]-[5]). Given a negative sign of the statistically significant parameter associated with public healthcare coverage, with other factors kept constant, excess distances tend to widen with lower coverage shares, with the remaining percent share tending to reflect private healthcare coverage. The presence of relatively lower proportions of female residents is found to be associated with greater hospital distances (Table 3). Hospital locations appear to be unaffected by differences in age composition or relative extent and incidence of poverty across communes (results not shown). To check for possible simultaneity and bi-directionality, for some explanatory variables endogeneity tests should be applied. For instance, hospital locations is likely to be influenced by healthcare planners' awareness of lesser needs in communes with a high proportion of non-permanent male migrants in working age, while willingness for closer vicinity to emergency hospitals may in turn discourage households from settling in remote areas. ${ }^{10}$

A systematic investigation of simultaneity and/or sample selection bias will become feasible with longer and more disaggregate time series. Relative to the availability of non-hospital medical centres, endogeneity testing can help shed lights on the broader framework. The Durbin-Wu-Hausman test fails to reject the null of exogeneity for the

(Table 2-3; Greene, 1998). Lack of convergence with a truncated-normal distributional assumption is not avoided with this rescaling.

10 Endogeneity is more effectively analysed with individual- or household-level data. For instance, based on CASEN surveys, the choice of public or private health insurance is found to largely depend on income, age and gender composition of households, and area of residence, since private health service providers are mainly located in high-density urban areas (Sapelli and Torche, 1998; Sanhueza and Ruiz-Tagle, 2002). At the cross-commune level examined here, the variable hscov has no statistically significant correlation with elderly or female population rates, among other variables. Public healthcare coverage and urbanisation rates are negatively correlated $(\mathrm{r}=-0.23$, i.e. $1 \%$ significance level given the panel sample size), and both variables influence municipal budget expenditures per capita in healthcare (see next sub-section and Table 4, model [10] and [11]). 
variable hsavail in model [3], with a statistically insignificant parameter associated with the residuals from the auxiliary regression model $([3 \mathrm{H}]$, Table 3, and [12], Table 4; Wooldridge, 2002: 119; Verbeek, 2004: 135). ${ }^{11}$ Relative to this variable, 74 missing observations out of the panel total of 1023 tend to be concentrated in a number of relatively small communes in peripheral regions, particularly in the South (Aisén, Reg. XI). For this reason and in view of the zero-bounded nature of this variable, ML truncated regression is preferable to OLS in the auxiliary regression (Greene, 2003a: 756-761). Non-hospital health services are found to be largely influenced by socio-economic and demographic-environmental factors, including urbanisation and area-specific effects, and have undergone negative time-related effects in the third biennium. Ceteris paribus and if the fixed-effect variable for log-transformed communal area is not included in model [12], residents of communes in the geographical extremes of the country, particularly in the North but also in the Patagonian regions, appear to be almost twice more reliant on the above services compared with in-between regions (Table 4: parameters in italics for dclimn and dclimes).

Across the stochastic frontier models, differences between $\lambda$ estimates (see section II and Table 3) in the half-normal versus exponential models for the inefficiency component are substantially reduced if account is taken of the true truncated-distribution variance in the half-normal distribution (i.e. by multiplying $\sigma_{\mathrm{u}}^{2}$ estimates by $0.36(=1-(2 / \pi))$ (Greene, 1998: 755). Relative to specification (i) versus (ii) above (sub-section 4.2), no clear evidence is found in support of one relative to the other. While specification (ii) tends to yield better regression fits, no substantial difference is found in terms of inefficiency estimates, except for few observations. Compared with model [4] (and its half-normal analogue [3], Table 3), in model [5] these observations (identifiable as outliers above the linear cluster in a cross-scatter plot of these estimates: Figure 2 (b)) induce a lesser degree of overdispersion (which is due to inclusion of regressors accounting for heteroscedastic location inefficiency), along with a larger signal-to-noise ratio (Table 3: $\theta$ vs. $\lambda$ estimates, [4] vs. [5]; the degree of overdispersion, measured by $\mathrm{V}(\mathrm{u}) / \mathrm{E}(\mathrm{u})>1$, is $1.67,2.23$ and 1.43, for [3], [4] and [5] respectively). In a one-step stochastic frontier model with $\ln \left(\sigma_{\mathrm{u}}\right)^{2}$ as a function of possible inefficiency determinants and control variables accounting for absence of medical personnel and health status, among others, the poverty headcount index appears to be the only variable with some explanatory role for location inefficiency (Table 3: [5]; other results not shown). However, its parameter is not found to be robust to alternative specifications. In model [5], the parameter signs for the nurses-to-doctors ratio variable and its square term match expectations of a hyperbolic pattern with relatively lesser location inefficiency in the middle, but parameter estimates are not statistically significant.

11 The power of the test is weakened by heteroscedastic residual patterns in stochastic frontier modelling. However, lack of statistical significance of the parameter associated with $\xi$ (Table 3 ) is also found with OLS estimation of the auxiliary regression and/or model $[3 \mathrm{H}]$. By construction, the first-stage reduced form regression [12] assumes that all independent variables in [3] (other than the variable to be tested, i.e. hsavail in this case) are exogenous (the parameter associated with the female population rate is statistically insignificant due to positive collinearity with the urbanisation rate). 


\section{TABLE 4}

SOCIAL DISTRIBUTION WEIGHTS IN PUBLIC HEALTHCARE: ORDERED PROBIT (HOSPITAL TYPE), TOBIT (INFRASTRUCTURE INVESTMENT), AND AUXILIARY TRUNCATED REGRESSION (NON-HOSPITAL MEDICAL CENTRES)

\begin{tabular}{|c|c|c|c|c|c|c|}
\hline Model & $\begin{array}{c}\text { ordered probit } \\
\text { [7] }\end{array}$ & $\begin{array}{l}\text { ordered probit } \\
{[8]}\end{array}$ & $\begin{array}{l}\text { ordered probit } \\
{[9]}\end{array}$ & $\begin{array}{l}\text { tobit } \\
{[10]}\end{array}$ & $\begin{array}{l}\text { tobit } \\
{[11]}\end{array}$ & $\begin{array}{c}\text { truncated regr. } \\
{[12]}\end{array}$ \\
\hline dep. variable & \multicolumn{3}{|c|}{ hord } & \multicolumn{2}{|c|}{ infrasr } & hsavail \\
\hline $\begin{array}{l}\text { constant } \\
\text { dclimn } \\
\text { dclims } \\
\text { dclimes } \\
\text { adm2 } \\
\text { adm3 } \\
\text { absmed } \\
\text { schly } \\
\text { hcpov } \\
\text { ipovr } \\
\text { birthr } \\
\text { epr } \\
\text { fpopr } \\
\text { lnarea } \\
\text { urb } \\
\text { nurpmd } \\
\text { nurpmdh13 } \\
\text { hslrev } \\
\text { lnexppc } \\
\text { hscov } \\
\text { lnmvis } \\
\text { medcons } \\
\text { outp } \\
\text { hepat } \\
\text { lnimr } \\
\text { tbc } \\
\text { u (distcens [3]) }\end{array}$ & $\begin{array}{c}-0.006(-1.05)^{\wedge} \\
-12.7(-3.98) \\
-1.001(-3.68) \\
-0.32(2.62) \\
-2.45(12.59) \\
0.02(7.28)\end{array}$ & $\begin{array}{c}-0.02(-3.24) \\
0.01(1.77) " \\
-14.02(-3.6) \\
0.12(0.4)^{\wedge}\end{array}$ & $\begin{array}{c}{[0.17,0,25]^{\wedge}} \\
-0.02(-1.03)^{\wedge} \\
5.21(2.2)^{\wedge}\end{array}$ & $\begin{array}{c}-0.53(-8.6)^{*} \\
-0.02(-1.77)^{\wedge} \\
-0.1(-0.31)^{\wedge} \\
0.02(21.3)^{*} \\
\\
-0.003(-0.9)^{\wedge} \\
0.03(3.48) \\
-0.23(-2.79)\end{array}$ & $\begin{array}{c}-0.46(-9.5) * \\
-0.03(-3.24) \\
-0.5(-1.98)^{\prime} \\
0.02(28.7) *\end{array}$ & $\begin{array}{c}1.29(1.71) " \\
0.68(4.41) \\
{[1.16](8.72)} \\
0.15(2.2) " \\
{[0.79](2.83)}\end{array}$ \\
\hline $\begin{array}{l}\text { te2 } \\
\text { te3 }\end{array}$ & & & & & $\begin{array}{l}-0.05(-0.1)^{\wedge} \\
-0.24(-0.6)^{\wedge}\end{array}$ & $\begin{array}{c}0.14(1.75) " \\
-0.26(-3.08)\end{array}$ \\
\hline $\begin{array}{l}\zeta(1) \\
\zeta(2) \\
\zeta(3)\end{array}$ & $\begin{array}{c}0.78(5.46) \\
1.15(6.9) \\
2.28(12.1)\end{array}$ & $\begin{array}{c}0.75(4.76) \\
1.1(6.44) \\
2.51(13.2)\end{array}$ & $\begin{array}{l}0.57(7.59) \\
0.87(10.2) \\
2.06(18.9)\end{array}$ & & & \\
\hline$\chi^{2}(\mathrm{k})$ & $455.2(6)$ & $219.2(6)$ & $322.9(7)$ & $2135.8(10)$ & $3059.6(8)$ & $1452.2(10)$ \\
\hline$\psi([10]-[11])$ & & & & $1.34(2.22)^{\prime}$ & $1.23(3.3)$ & \\
\hline $\begin{array}{l}\sigma\left(\varepsilon_{1} \mid \varepsilon_{2}\right) \\
\sigma(\varepsilon)([12])\end{array}$ & & & & $3.55(50.9)$ & $3.54(63.2)$ & $0.64(29.3)$ \\
\hline Pseudo $\mathrm{R}^{2}$ & 0.24 & 0.21 & 0.19 & $0.71(0.72)$ & $0.71(0.73)$ & 0.64 \\
\hline $\begin{array}{l}\text { \% correct } \\
\text { (htype } 1,2,3,4+5 \text {, } \\
\text { no hospital) } \\
\mathrm{N}\end{array}$ & $\begin{array}{c}0.61 \\
(0.79,0,0,0.54 \\
0.87) \\
686\end{array}$ & $\begin{array}{c}0.79 \\
(0,0,0,0.65 \\
0.96) \\
545\end{array}$ & $\begin{array}{c}0.61 \\
(0.1,0,0,0.65, \\
0.82) \\
664\end{array}$ & $577(427)$ & $845(626)$ & 840 \\
\hline
\end{tabular}

Notes: T-statistics in parentheses (significance level: Table 3). [9]: parameter estimate ranges in bracketsitalics for re-specifications with inclusion of absmed, lnimr, and/or replacement of medcons with lnmvis. [10]-[11]: *parameters of auxiliary regression on lnexppc, with recursive FIML; in italics, parameter/t-stat. for location inefficiency variable (u), with $a d m 3$ excluded in [10] $\left(\mathrm{Ps}_{\mathrm{R}} \mathrm{R}^{2}\right.$ and $\mathrm{N}$ in italics). [12]: t-tests based on heteroscedasticity-adjusted standard errors (for parameters in italics, see section IV). Nurpmdh13 slope dummy (nurpmd) $\cdot(h t 1+h t 3)$ ( 0 for other hospital categories and no hospital services). $\zeta(i)$ threshold parameters. $\chi^{2}(\mathrm{k})$ LR test of fitted versus intercept-only $\log$-likelihood ( $k$ excluding $\zeta(i)$ in [7]-[9]; including constant of auxiliary regression in [10]-[11]). $\psi=\left(\sigma_{12} / \sigma_{2}^{2}\right)\left(=0\right.$ no endogeneity in lnexppc, $t$-stat. in parentheses). Pseudo $\mathrm{R}^{2}$ (McFadden) likelihood ratio index. $N$ sample size. 


\subsection{Ordered probit and tobit regression estimates and AKS indices}

Municipal planning decisions influencing the static allocation of hospital services and its dynamic adjustment process can be partly captured by estimated parameters in ordered probit and tobit models. These models are geared to explain cross-commune patterns of hospitals by complexity of services offered and the share of infrastructure investment in municipal healthcare expenditures, respectively. Selected regression results are shown in Table 4. Relative to the ordered probit models, the sign of parameter estimates is indicative of the overall effect of a variable on a latent variable of service complexity (proxied in reverse terms by the multinomial variable $\operatorname{hord}(j)$ : see explanation under htype $(j)$ in Table 2 ). In ordered probit models, marginal effects for low categories typically have the opposite signs relative to estimated parameters, with in-between effects for intermediate categories (Verbeek, 2004: 204; Greene, 2003a: 738). ${ }^{12}$ Time effects are not found to exercise a statistically significant impact over the six-year period, for both dependent variables (relative to infrastructure investment, see model [11]). Based on general hypotheses discussed in section III, the cross-commune allocation of healthcare services by type of hospital is modelled here with control variables accounting for urban environment, healthcare system heterogeneity, health service use, and morbidity and health status risk. Multicollinearity problems prevent the simultaneous use of the respective proxy variables and other covariates $(e . g$. with positively collinear variables for housing water supply, schooling and urbanisation) in the same regression.

Similarly to stochastic frontier regression results, remote communes with unbalanced (low) female-to-male population ratios tend to be less likely to rely on high-category hospitals as nearest emergency options. The same also applies to communes with relatively higher shares of elderly residents and less urbanised areas (Table 4: [7], [9], although not [8]). In the ordered probit regressions, opposite to results in the stochastic frontier models [3]-[5], ceteris paribus a higher public healthcare coverage positively affects the dependent variable. This implies some degree of spatial disparity in terms of this criterion: communes with relatively greater reliance on FONASA -public health service- are less likely to benefit from emergency hospitals with specialised medical care. If specific features of healthcare demand and supply are focused on, specialised hospitals turn out to be mainly located in communes registering relatively higher rates of patients' hospitalisation and notification of tuberculosis, while discordant indications concern the role of medical consultation rates based on alternative indicators (model [9]). Relative to tuberculosis notification rates, this result is likely to be driven by a combination of timely detection and treatment in communes with easier access to type- 1 hospitals, and, conversely, frequency of possibly late notification cases in some of the relatively less served, more remote communes.

12 However, in the absence of a continuous and smooth conditional mean function, ad hoc formulae used to approximate marginal effects may yield results in contrast with theoretical expectations, depending on threshold estimates and ML procedure (Greene, 1998: 499, 504; marginal effect estimates for models [7]-[9], and regression parameter estimates based on the alternate communal poverty ratios, are not shown for space reasons). 
Along with type- 3 and to a greater extent than type- 2 hospitals, type- 1 hospitals tend to require higher medical-to-paramedical personnel ratios (nurpmdh13, model [7]). However, apart from the impact in terms of type- 1 hospital choices, the inclusion of this specific feature fails to redress the lack of predictive power for upper-intermediate levels of hospital categories. Similarly, relative to other covariates (as it can be visualised in Figure $1(a)$ ), the negative parameter associated with the poverty headcount index is largely 'driven' by a major bulk of hospital categories concentrated in communes with type-4 hospitals (= hord3, with inclusion of non-classified category) or lack of hospital services $(=$ hord 4$)$. A similar pattern appears to induce a positive sign in the estimated parameter associated with the relative incidence of absolute poverty within the poor (model [8], and Figure $1(b)$ ). By contrast, if attention is focused on the first four hospital/healthcare categories (highly equipped, with specialties, with basic specialties, and general practitioners' services), a location bias in healthcare against relatively poorer communes is evident in terms of urban poverty headcounts (Figure $1(c)$ ). The substantial gap between presence and absence of hospital facilities is revealed by respective threshold parameter values nearly twice as high compared with immediately preceding thresholds (Table 4: $\zeta(3)$ ). Location inefficiency, proxied by estimated residuals $u_{j t}(=\mathrm{E}(u \mid v+u))$ from the SCF model [3] (Table 3), does not turn out to be a relevant determinant of spatial distribution of hospitals by type (e.g. parameter estimate in [8], Table 4), nor to have significant interactions with incidence of transmittable diseases across communes (correlation coefficients of 0.02 and -0.01 with tuberculosis and hepatitis notification rates, respectively).

Relative to tobit specifications for healthcare infrastructure expenditures, a simultaneous equation estimation is applied, so as to jointly model the dependent variable with endogeneity testing for one of the covariates, namely log-transformed health expenditures per capita. High municipal budget per capita health expenditures are found to be largely influenced by relatively larger public healthcare coverage and lower urbanisation (one should notice that differences in parameter sizes are influenced by different scaling in percent rates: see Table 2). In turn, investment decisions for hospital infrastructures appear to have been taken particularly in the absence of substantial health expenses per capita, with the latter possibly reflecting (given the above relationships) tighter budget constraints for more immediate medical care needs. The exogeneity hypothesis on this variable (lnexppc) is rejected by t-tests on the autocorrelation parameter linking residuals from the two regressions (Table 4: $\psi$ in model [10] and [11]; Greene, 1998: 685). In this respect, one should notice that likelihood ratio (LR) test results are inflated by the simultaneous auxiliary regression estimation.

Based on alternative tobit specifications, no significant influence in the allocation of infrastructure investments appears to be clearly attributable to public healthcare supply and demand factors across communes. Exceptions are given by a statistically significant positive parameter for tuberculosis notification, thus implying efforts to support communes with high notification rates, and relatively stronger investment efforts in communes without municipal healthcare service, particularly in Southern regions (although not in the extreme South; see dummy variable estimates in [10] and 


\section{FIGURE 1}

HEALTHCARE TYPE VERSUS EXTENT OF POVERTY AND RELATIVE INCIDENCE OF ABSOLUTE POVERTY: CROSS-COMMUNE PLOTS

(a)

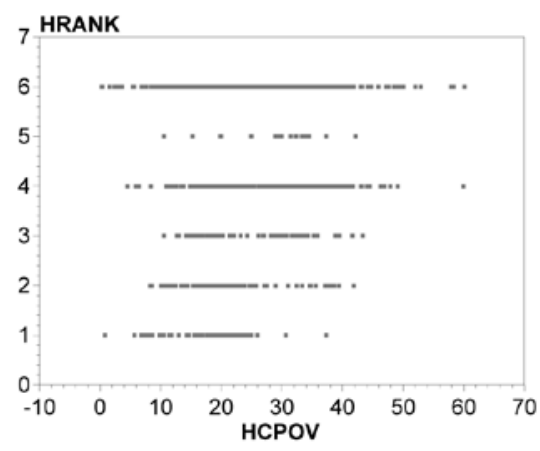

(c)

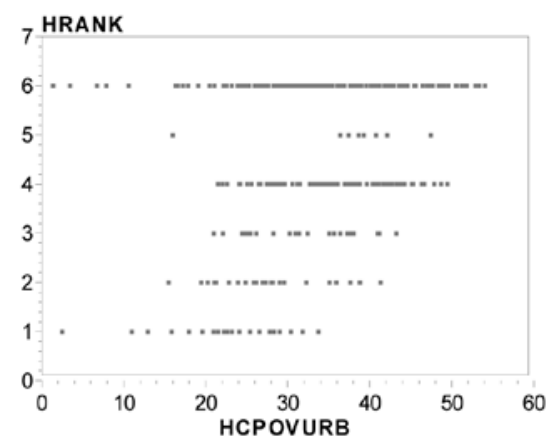

(b)

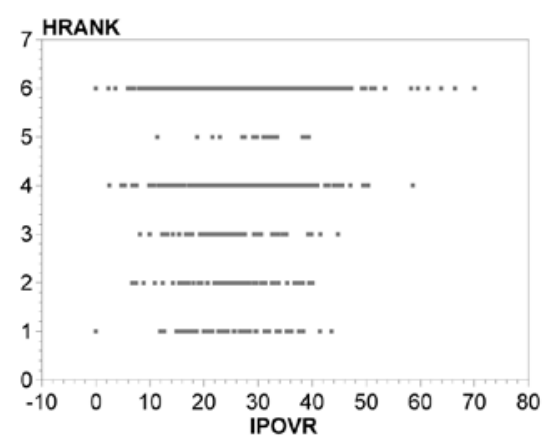

(d)

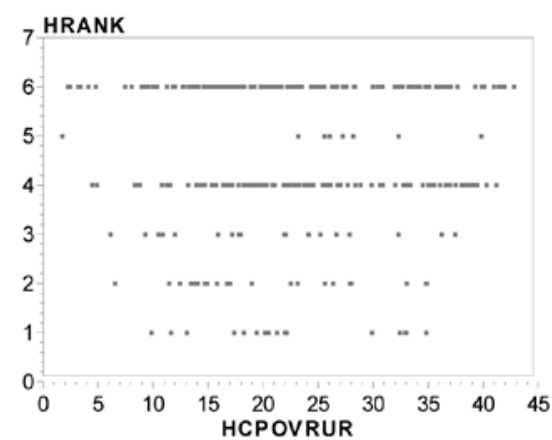

Poverty headcounts for urban (hcpovurb) and rural (hcpovrur) areas are communal estimates based on 2003 CASEN and 2002 census data (Agostini, Brown and Góngora, 2008: Ap. 4).

[11], Table 4: adm3 and dclims). However, healthcare infrastructure development is not found to be influenced by other social welfare criteria, reflected by proxies for poverty and age composition, among others. Moreover, in view of estimation results if a location inefficiency proxy is added (excess distance residuals $u$ from model [3]), hospital infrastructure upgrading does not turn out to have been implemented towards the objective of reducing cross-commune disparities in terms of spatial access inequality, rather it followed an opposite direction (see estimated parameters in italics associated with $u$ (distcens [3]) in [10]-[11] in Table 4). 
Relative to the first biennium and 196 communes with available CASEN survey information, a correlation analysis of inefficiency residuals from alternative models versus proxies for quality perceptions of public healthcare services highlights how communes with more commonly perceived inadequacy in timing of medical attention are often among those with relatively larger location inefficiency (Table 5 and Appendix). Excess distance residual patterns do not substantially vary across different stochastic frontier specifications and distribution assumptions, as highlighted by correlation analysis and atypical observations (Table 5 and Figure 2). Based on the AKS distanceinequality index [1] in section II, commune-level indices of access inequality can be estimated, with distance frontier estimates used as a proxy for EDE distances and actual (5 km-censored) hospital distances taken as average hospital distances for residents within each commune. A comparison among different stochastic frontier models yields similar index estimates for the relatively more disadvantaged communes in terms of excess distances, with three communes in the North identified as the most critical cases (Table 5). The AKS indices are indicative of a relative welfare loss measured in terms of estimated commune-specific 'best practice' hospital distances. For these communes, the excess burden of difficult access to hospital services amounts to nearly $80 \%$ relative to this yardstick.

\section{TABLE 5}

LOCATION INEFFICIENCY, QUALITY PERCEPTIONS AND AKS INEQUALITY INDEX ESTIMATES FOR CHILEAN HOSPITALS

\begin{tabular}{|l|c|c|c|c|}
\hline correlation coefficients & $\mathrm{u}[3]$ & $\mathrm{u}[3 \mathrm{rev}]$ & $\mathrm{u}[6]$ & $\mathrm{u}[6 \mathrm{exp}]$ \\
\hline $\mathrm{u}[3]$ & & 0.98 & 0.97 & 0.97 \\
$\mathrm{u}[3 \mathrm{rev}]$ & & & 0.98 & 0.99 \\
$\mathrm{u}[6]$ & & & & 0.99 \\
absimp (1998 survey vs. 2000-01 u) & -0.12 & -0.14 & -0.11 & -0.14 \\
abstim (1998 survey vs. 2000-01 u) & 0.44 & 0.46 & 0.46 & 0.47 \\
\hline hospital distance-inequality indices (in italics: highest I(D) commune-level estimates within model) \\
\hline Colchane (Reg. I, 2000-01) & 0.858 & 0.864 & 0.765 & 0.816 \\
María Elena (Reg. II, 2004-05) & $($ missing) & $($ missing) & 0.786 & 0.827 \\
Illapel (Reg. IV, 2004-05) & 0.786 & 0.814 & 0.791 & 0.811 \\
sample size & 641 & 633 & 692 & 692 \\
\hline
\end{tabular}

Location inefficiency estimates from stochastic cost frontier hurdle models ( $5 \mathrm{~km}$. threshold):

[3] results from model [3] (Table 3, $u \sim \mathrm{N}^{+}\left[\mu_{\mathrm{u}}, \sigma_{\mathrm{u}}^{2}\right]$ )

[3rev] distcens $=\mathrm{f}\left(\right.$ dumlac, dummac, hscov, fpopr, hsavail) (revised model [3], $u \sim \mathrm{N}^{+}\left[\mu_{\mathrm{u}}, \sigma_{\mathrm{u}}{ }^{2}\right]$ )

[6] results from model [6] (Table 3, $u \sim \mathrm{N}^{+}\left[\mu_{\mathrm{u}}, \sigma_{\mathrm{u}}^{2}\right]$ )

[6exp] results from model [6] (with $u \sim \Gamma\left[1 / \theta, 1 / \theta^{2}\right]$ ) 


\section{FIGURE 2}

\section{STOCHASTIC FRONTIER RESIDUAL CROSS-PLOTS (ALTERNATIVE SPECIFICATIONS AND DISTRIBUTIONAL ASSUMPTIONS)}

(a)

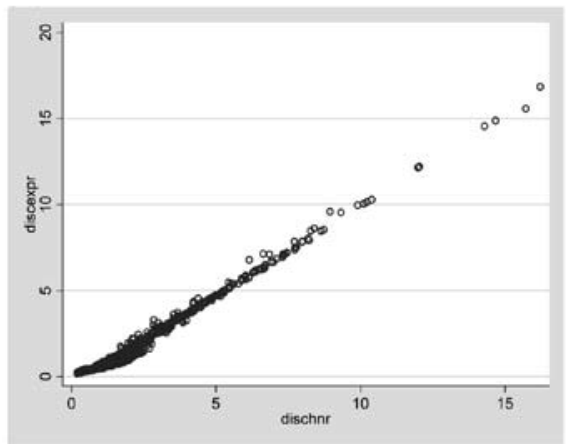

(b)

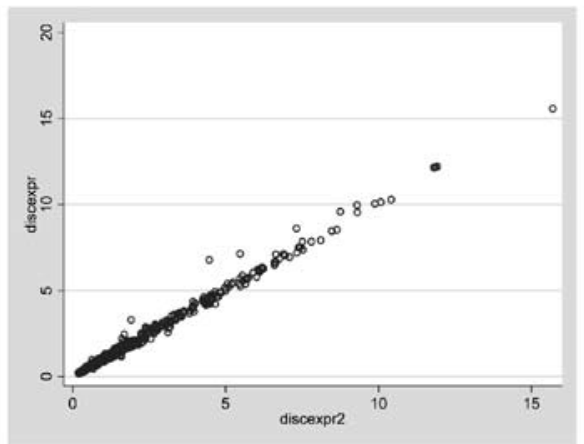

Location inefficiency estimates from censored distance regressions (excluding high-leverage observations for the commune of Colchane, Reg. I): model [3], half-normal residuals (dischnr); model [4], negative exponential residuals (discexpr); model [5], negative exponential residuals, with zero parameter restrictions for nurpmd and nurpmd ${ }^{2}$ (discexpr2) (see Table 3).

\section{CONCLUSION}

Of two complementary approaches to healthcare planning for poverty alleviation, narrow targeting helps identify areas with severe problems of accessibility and lower standards of healthcare and other public utilities, while social policy targeting is focused among others on reshaping public expenditures, which often implies increased attention to primary healthcare, and to clinics concerned with basic healthcare, as opposed to general hospital expenditures. Besides the choice of a balanced mix between the two approaches aimed at minimising programme inefficiencies and failed coverage, an additional concern arises from possible negative side-effects caused by the way in which these measures may be implemented. ${ }^{13}$

In Chile, improvements in targeting, geared to identify poor households and provide specific support to worse-off neighbourhoods (such as subsidised electricity and sewerage), have gradually been introduced in the last fifteen years. However,

13 Specific costs of narrow targeting, such as behavioural responses by beneficiary and non-beneficiary groups, are discussed by van de Walle (1998). Similar incentive effects can be envisaged for geographical targeting, particularly if the spatial breakdown of target areas is not sufficiently narrow as to prevent potential gainers from moving into these areas, thus impinging upon the rationale of the programme (Bigman et al., 2000: 169). An example of a broad targeting approach relative to basic food subsidies is discussed in Alderman and Lindert (1998). 
conditions attached to some of these measures, as the prohibition to sell or rent subsidised houses, are considered to have discouraged potential relocation decisions, thus failing to contribute to a remarkable reduction of socio-economic disparities across and within regions (Soto and Torche, 2004). More generally, persistent high cross-commune welfare inequality is evidenced by Agostini and Brown (2007), and social expenditures do not appear to have been sufficiently oriented towards poverty alleviation. Relative to the healthcare sector, the 1981 partial privatisation of the health insurance system, and the concurrent process of decentralisation of public primary healthcare to municipalities, were meant to foster efficiency in the sector. Social and regional imbalances, including unfair access to healthcare services, did not receive the same attention. According to a 2006 survey, more than half of respondents were dissatisfied with the availability and quality of healthcare services in Chile, which is likely to be the consequence of both enduring deficiencies and access shortfalls, and rising expectations (Savedoff, 2007: 13). Since the late 1990s, the Chilean Ministry of Health has undertaken studies on healthcare in each of the 13 Regions, aimed at identifying investment priorities for the public health sector (Arteaga, Astorga and Pinto, 2002).

This analysis has striven to gain insights in this direction, based on hypotheses and econometric model specifications which are of potential use for similar tests on other countries. The influence of socio-economic, demographic and geophysical factors on excess hospital distances across Chilean communes is evidenced by parameter estimates for a number of variables, including indirect determinants which explain the availability of non-hospital medical centres. Given the relatively short time span analysed, no shifts are observed in the cross-commune distance frontier and location inefficiency, while time-invariant characteristics (or features with these characteristics within the relatively short period analysed, including institutional factors and local transport network) account for partly unobserved heterogeneity across communes. Healthcare location inefficiency is found to be robust to different model specifications and distribution assumptions, and appears neither to have a significant influence on location choices of hospitals by type of healthcare services or infrastructure investments for hospital construction and upgrading, nor to interact in a systematic way with the relative incidence of notified transmittable diseases. The relative extent of poverty turns out to be the only covariate able to explain hospital location inefficiency, although not consistently throughout different stochastic frontier specifications. To pursue more equitable healthcare accessibility, public authorities should devote more resources to communes with widespread presence of poor households, especially in some remote areas of the country. These communes tend to be in a disadvantaged position for exercising pressures for compensatory allocation measures at a nation-wide level, and require ad hoc interventions in terms of family-community care and outreach activities (Hertel-Fernandez, Giusti and Sotelo, 2007). As an additional tool for effective targeting of healthcare services, the analysis could be extended to more disaggregate intra-communal data within regions, thus focusing on household characteristics, and accessibility and standards of these services at a microeconomic level. 


\section{REFERENCES}

AGOSTINI, C.; P. BROWN and D.P. GONGORA (2008). "Distribución espacial de la pobreza en Chile", Estudios de Economía 35 (1), pp. 79-110.

AGOSTINI, C. and P. BROWN (2007). "Desigualdad geográfica en Chile”, Revista de Análisis Económico 22 (1), pp. 3-33.

ALDERMAN, H. and K. LINDERT (1998). "The Potential and Limitations of Self-Targeted Food Subsidies", World Bank Research Observer 13 (2), pp. 213-229.

ARTEAGA, O.; I. ASTORGA and A.M. PINTO (2002). "Desigualdades en la provisión de asistencia médica en el sector público de salud en Chile", Cadernos de Saúde Pública 18 (4), pp. 1053-1066.

ARTEAGA, O.; S. THOLLAUG; A.C. NOGUEIRA and C. DARRAS (2002a). "Información para la equidad en salud en Chile", Revista Panamericana de Salud Pública 11 (5-6), pp. 374-385.

BACCOUCHE, R. and M. KOUKI (2003). "Stochastic Production Frontier and Technical Inefficiency: A Sensitivity Analysis", Econometric Reviews 22 (1), pp. 79-91.

BARRETT, G.; T. CROSSLEY and C. WORSWICK (1999). "Demographic Trends and Consumption Inequality in Australia 1975-1993”, CEPR Discussion Paper Series No 403, Australian National University (econrsss.anu.edu.au).

BATTESE, G. and T. COELLI (1995). "A Model for Technical Inefficiency Effects in a Stochastic Frontier Production Function for Panel Data", Empirical Economics 20 (2), pp. 325-332.

BERGER, M. and J. MESSER (2002). "Public Financing of Health Expenditures, Insurance, and Health Outcomes", Applied Economics 34 (17), pp. 2105-13.

BIGMAN, D. and U. DEICHMANN (2000). "Spatial Indicators of Access and Fairness for the Location of Public Facilities", in D. Bigman and H. Fofack (Eds.), Geographical Targeting for Poverty Alleviation. Methodology and Applications, Regional and Sectoral Studies Series, World Bank, Washington DC, pp. 181-205.

BIGMAN, D. ; S. DERCON ; D. GUILLAUME and M. LAMBOTTE (2000). "Community Targeting for Poverty Reduction in Burkina Faso”, World Bank Economic Review 14 (1), pp. 167-193.

BIXBY, L. and D. GÜELL (1999). "Oferta y acceso a los servicios de salud en Costa Rica: estudio basado en un sistema de información geográfica (GIS)", Investigaciones en Salud Pública (Documentos Técnicos), División de Salud y Desarrollo Humano, PAHO-WHO, Washington DC.

BOSSERT, T. (2000). "La descentralización de los sistemas de salud en Latinoamérica: un análisis comparativo de Chile, Colombia y Bolivia”, HSR (Health Sector Reform) Initiative N ${ }^{\circ} 29$, Harvard School of Public Health (www.lachsr.org).

BRENT, R.J. (1991). "On the Estimation Technique to Reveal Government Distributional Weights", Applied Economics 23 (5), pp. 985-992.

BRENT, R.J. (1986). "An Axiomatic Basis for the Three-Objective Social Welfare Function within a Poverty Context", Economic Letters 20 (1), pp. 89-94.

FARSI, M.; M. FILIPPINI and M. KUENZLE (2004). "Cost Efficiency in Regional Bus Companies: An Application of Alternative Stochastic Frontier Models", CEPE Working Papers $\mathrm{N}^{\circ} 33$, ETH, Zurich.

FIELDS, G. (2003). "Should Poverty and Inequality Measures Be Combined?”, Cornell University (www. ilr.cornell.edu/directory).

FOSTER, J.; J. GREER and E. THORBECKE (1984). "A Class of Decomposable Poverty Measures", Econometrica 52 (3), pp. 761-766.

GADIKOU, E.; C. MURRAY and J. FRENK (2000). "Measuring Preferences on Health System Performance Assessment", GPE Discussion Paper Series No 20, WHO, Geneva.

GOLAN, A.; J. PERLOFF and X. WU (2001). "Welfare Effects of Minimum Wage and Other Government Policies", CUDARE Working Papers N 957, Department of Agricultural and Resource EconomicsUCB, Berkeley (repositories.cdlib.org/are_ucb).

GONZÁLEZ, C.; X. AGUILERA; A. GUERRERO; V. CHILD-GOLDENBERG and H. GEORGI (2000). "Indicadores comunales para el estudio de la desigualdad en salud", Boletín de vigilancia en salud pública de Chile 3 (11), pp. 7-13 (epi.minsal.cl/epidemologia).

GREENE, W.H. (2003). "Distinguishing between Heterogeneity and Inefficiency: Stochastic Frontier Analysis of the WHO's Panel Data on National Health Care Systems", Stern School of Business, New York University (www.stern.nyu.edu). 
GREENE, W.H. (2003a). Econometric Analysis, Prentice Hall, New Jersey.

GREENE, W.H. (1998). LIMDEP Version 7.0. User's Manual, Econometric Software Inc., New York.

GUPTA, N.; P. ZURN; K. DIALLO and M. DAL POZ (2003). "Uses of Population Census Data for Monitoring Geographical Imbalance in the Health Workforce: Snapshots from Three Developing Countries", International Journal for Equity in Health 2 (11) (www.equityhealthj.com).

HERTEL-FERNANDEZ, A.; A. GIUSTI and J. SOTELO (2007). "The Chilean Infant Mortality Decline: Improvement for Whom? Socioeconomic and Geographic Inequalities in Infant Mortality", Bulletin of the World Health Organization 85 (10), pp. 733-820.

HOWARD, D. (2005). "Quality and Consumer Choice in Healthcare: Evidence from Kidney Transplantation", Topics in Economic Analysis and Policy 5 (1) (www.bepress.com).

JAMES, C.; G. CARRIN; W. SAVEDOFF and P. HANVORAVONGCHAI (2005). "Clarifying EfficiencyEquity Tradeoffs through Explicit Criteria, with a Focus on Developing Countries", Health Care Analysis 13 (1), pp. 33-51.

JONDROW, J.; C. KNOX LOVELL; I. MATEROV and P. SCHMIDT (1982). "On the Estimation of Technical Inefficiency in the Stochastic Frontier Production Function Model”, Journal of Econometrics $19(2 / 3)$, pp. 233-238.

KODDE, D. and F. PALM (1986). "Wald Criteria for Jointly Testing Equality and Inequality Restrictions", Econometrica 54 (5), pp. 1243-1248.

MAINARDI, S. (2007). "Unequal Access to Public Healthcare Facilities: Theory and Measurement Revisited", Surveys in Mathematics and its Applications 2, pp. 91-112.

MAINARDI, S. (2003). "Social Welfare Objectives and Distribution Weights in Public Health Planning in Turkey", Journal for Studies in Economics and Econometrics 27 (3), pp. 29-47.

MCFADDEN, D. (1976). "The Revealed Preferences of a Government Bureaucracy: Empirical Evidence", Bell Journal of Economics 7 (1), pp. 55-72.

MINISTERIO DE PLANIFICACION (MIDEPLAN) (2006). Encuesta CASEN 2006, División Social, Santiago (www.mideplan.cl).

MIDEPLAN (2004). "Pobreza y distribución del ingreso en las regiones", Serie CASEN, División Social, Santiago.

MINISTERIO DE SALUD (MINSAL) - PONTIFICIA UNIVERSIDAD CATOLICA (PUC) (2004). Resultados I Encuesta de Salud, Chile 2003, Departamento de Epidemiología, Santiago.

OLIVER, A. and E. MOSSIALOS (2004). "Equity of Access to Health Care: Outlining the Foundations for Action", Journal of Epidemiology and Community Health 58 (8), pp. 655-658 (www.pubmedcentral.nih.gov).

OXOBY, R. and D. BISCHAK (2005). "Passing the Time: Other-Regarding Behavior and the Sunk Cost of Time", Discussion Papers, $\mathrm{N}^{\circ}$ 2005/03, University of Calgary (econ.ucalgary.ca).

PERTICARA, M. and C. SANHUEZA (2008). "La compleja tarea de identificar quién es pobre”, Observatorio Económico 14 (www.economiaynegocios.uahurtado.cl).

PIZZOLITTO, G. (2005). "Poverty and Inequality in Chile: Methodological Issues and a Literature Review", CEDLAS, Universidad Nacional de la Plata (www.defeco.econo.unlp.edu.ar/cedlas).

PUIG-JUNOY, J. and V. ORTUN (2003). "Cost Efficiency in Primary Care Contracting: A Stochastic Frontier Cost Function Approach", Universitat Pompeu Fabra (www.econ.upf.edu/docs/papers).

RITTER, C. and L. SIMAR (1997). "Pitfalls of Normal-Gamma Stochastic Frontier Models", Journal of Productivity Analysis 8 (2), pp. 167-182

SANHUEZA, R. and J. RUIZ-TAGLE (2002). "Choosing Health Insurance in a Dual Health Care System: The Chilean Case", Journal of Applied Economics 5 (1), pp. 157-184 (www.cema.edu.ar).

SAPELLI, C. and A. TORCHE (1998). "El seguro provisional de salud: determinantes de la elección entre seguro público y privado, 1990-1994", Cuadernos de Economía 35 (106), pp. 383-406 (www. economia.puc.cl).

SAVEDOFF, W. (2007). "A Moving Target: Universal Access to Healthcare Services in Latin America and the Caribbean", Report submitted to the IDB (www.iadb.org/res/publications).

SIMSON, H. (2006). "Productivity in Public Services", CMPO Working Papers, № 07/164, University of Bristol (www.bus.ac.uk/depts/CMPO).

SMITH, P. and A. STREET (2005). "Measuring the Efficiency of Public Services: The Limits of Analysis", Journal of the Royal Statistical Society 168 (2), pp. 401-417. 
SOTO, R. and A. TORCHE (2004). "Spatial Inequality, Migration and Economic Growth in Chile", Cuadernos de Economía 41 (124), pp. 401-424.

THIEDE, M. and D. MCINTYRE (2008). "Information, Communication and Equitable Access to Health Care: A Conceptual Note", Cadernos de Saúde Pública 24 (5), pp. 1168-1173 (www.scielo.br).

VERBEEK, M. (2004). A Guide to Modern Econometrics, J. Wiley, Chichester-UK.

VISWANATHAN, K.; Y. JEON; I. OMAR; J. KIRKLEY and I. SUSILOWATI (2000). "Technical Efficiency and Fishing Skill in Developing Country Fisheries: The Kedah, Malaysia Trawl Fishery", IIFET 2000 Proceedings, International Institute of Fisheries Economics and Trade, Oregon State University (www.st.nmsf.gov).

WALLE, D. VAN DE (1998). “Targeting Revisited”, World Bank Research Observer 13 (2), pp. 231-248.

WANG, H. and P. SCHMIDT (2002). "One-step and Two-step Estimation of the Effects of Exogenous Variables on Technical Efficiency Levels", Journal of Productivity Analysis 18 (2), pp. 129-144.

WOOLDRIDGE, J. (2002). Econometric Analysis of Cross-Section and Panel Data, MIT Press, Cambridge, Massachusetts. 


\section{APPENDIX}

\section{DATA, VARIABLES AND MEASURES OF ACCESS SHORTFALLS}

In this analysis, relatively smaller communes are under-represented, since indicators of health status and poverty, among others, are either unavailable or relatively less reliable (and as such they are not included in the panel database). Poverty is defined relative to basic needs expenditures, absolute poverty relative to minimum food requirements, with different income poverty lines for urban and rural areas (Mideplan, 2004). In this respect, CASEN mainly relies on income (instead of consumption) data, thus failing to avoid problems of non-response (estimated to correspond to nearly $6 \%$ of the individuals selected to respond the survey; Pizzolito, 2005), misreporting and discrepancies. These problems are partly redressed through income imputationbased estimation by CEPAL. However, despite improvements in sampling design and accuracy, CASEN income data, while regarded to be representative at a regional level, are questioned in terms of communal representativeness, and would also need corrections and adjustments geared to distinguish between urban and rural areas within each commune, to discount subsidies from income estimates, and to update the basic baskets (Agostini, Brown and Góngora, 2008; Perticara and Sanhueza, 2008).

For ordered probit regressions, the few communal cases with type-5 hospitals have been lumped together here with type-4 hospitals, while a separate category defines lack of hospital services in a commune, namely availability of non-hospital medical centres only (Table 2: $h t y p e(j)$ vs. $h o r d(j))$. As proxies for public healthcare quality perceptions for the first biennium, in the absence of updated survey information, this analysis has relied on two dummy variables related to responses of healthcare users (registered with either public or private insurance system) in the 1998 CASEN survey (www.ine.cl/canales/chile_estadistico/territorio, 'panorama comunal'). Perceived absence of improvements in the commune's public healthcare system over 1996-98 (two years preceding the survey), and insufficient timely attention (i.e. 'some or strong delays') by medical personnel in public hospitals and medical centres in cases of illness, accident or delivery in 1998, are captured by the variables absimp and abstim, respectively (see Table 2).

As a healthcare output indicator, no statistical information is available at a crosscommune level for a composite final output directly concerned with improvements in health status of the population, such as quality-adjusted life expectancy. An exception is provided by González et al. (2000), but this is limited to average 1994-98 communal estimates of years of potential life lost. Alternative indicators of healthcare output can focus on (i) intermediate outputs related to infrastructure, standards and service quality (Table 2: hsavail, htype, absimp, abstim) or to coverage and use (hscov, lnmvis, medcons, outp, Inexppc), or (ii) final outcomes associated with specific problems of morbidity and mortality (hepat, tbc, lnimr). Since improvements in quality and modality of delivery are bound to reduce the healthcare activities (in terms of number of medical visits) needed to provide the same service, healthcare productivity and effectiveness 
can be measured by jointly examining the evolution of both sets of (intermediate and final output) indicators (Simson, 2006).

Two sets of measures are used for an assessment of shortfalls and unfairness in accessibility to provision of public services, namely statistical measures of dispersion and inequality (such as the mean absolute deviation -MAD- or the Gini coefficient), and, alternatively, poverty indices applied to public service supply shortages. Within both of these approaches, shortfalls can be measured in absolute (e.g., the standard deviation), or relative terms (such as the Gini coefficient and commonly used poverty indices). Regarding income in relative terms, one can refer to either a yardstick invariant to economic variables other than inflation (as in Sen's and Foster, Greer and Thorbecke (1984)'s poverty measures), or to time-varying income thresholds which depend on changes in others' real incomes and other variables (Fields, 2003). Alternative normative preferences may or may not assign a higher weight to outlying observations (e.g., standard deviation vs. MAD, and analogously for poverty indices, relative to a poverty aversion parameter) (Bixby and Güell, 1999; Gadikou, Murray and Frenk, 2000).

Unlike dispersion-related measures, the AKS family of inequality indices (see section II) complies with the Lorenz dominance criterion, whereby a distribution is more equal than another if it is possible to move from the latter to the former distribution through transfers from richer to poorer households. The Gini coefficient (which can be formulated so as to be interpreted as a special member of the AKS family, but without a 'normative' EDE income: Barrett, Crossley and Worswick, 1999) theoretically also satisfies this criterion. However, if two Lorenz curves intersect, it is difficult to rank one distribution as more equal than another by dominance criterion alone. With transfers being weighted in terms of rank gaps, instead of share differences as in AKS indices, the Gini coefficient is regarded as inferior to standard AKS-type indices, due to lesser sensitivity to incomes (/distances) in the lower (/higher) tail of the distribution and associated transfer policies, and conversely a high sensitivity to changes in the densest part -likely to be in the middle- of a distribution (Barrett, Crossley and Worswick, 1999: 6; for a detailed discussion, see also Golan, Perloff and $\mathrm{Wu}, 2001$ ). 